\title{
Digitalization Changing Work: Employees' view on the benefits and hindrances
}

\author{
Jussi Okkonen¹, Vilma Vuori², Miikka Palvalin², \\ 1,2 Tampere University, FIN-33014 Tampere University, Finland \\ jussi.okkonen@uta.fi, \{vilma.vuori,miikka.palvalin\}@tut.fi
}

\begin{abstract}
The Digitalization of work may enable better use of knowledge, which is expected to result in enhanced productivity and efficiency. Different organizations adopt digital ways of working, products, services and processes in different ways and paces. The extent and pace of capitalizing digitalization's potential in organizations has much to do with human attitude, ability to learn and the possibilities provided to use it in work. When looking digitalization from the employee viewpoint, it seems that the great expectations are not easily fulfilled. In fact, the effects of digitalization may be negative. This paper discusses the expectations and fears employees have towards digitalization changing their work. The issue is approached by using a qualitative data gathered along a survey. The aim was to find out if they see the effects digitalization has on their work as positive, negative, or something else, and which areas are highlighted
\end{abstract}

Keywords: digitalization, digitalization of work, benefits, hindrances, employees

\section{Introduction}

Digitalization has been understood to be a key driver of globalization for a long time. Organizations can operate without the restraints of time and presence as technological developments enable easier, faster and more affordable interaction among people. Consequently, digitalization has enabled entirely new business models and value creation mechanisms $[1,2,3]$. In fact, digitalization has rearranged the economics and business environments of organizations and simultaneously it has remodeled the ways people work.

Digitalization of work may enable better use of knowledge $[4,5]$ which is expected to result in enhanced productivity $[6,7,8,9,10]$ and efficiency $[11,12,13]$. However, when looking digitalization from the employee's viewpoint, it seems that the great expectations are not easily fulfilled. In fact, the effects of digitalization seem to be twofold: By bringing about ever more information systems, applications, user interfaces and operating systems to enhance productivity and efficiency of work, digitalization has led to increasing information load, hectic pace of work, multitasking, and interruptions [14]. Studies confirm that users can experience ICT as demanding and stressful $[15,16,17]$. Another rather negative result of digitalization is potential weakening of social ties and reducing social inclusion: by increased use of ICT people tend to have less face-to-face contacts [18] and in work context this may lead to weakening sense of community, and consequently issues with trust and motivation. Consequences of inadequate information systems, such as decreased job satisfaction 
and engagement with the organization[19], can negatively affect work quality and productivity [14].

Digitalization of work is a multilevel phenomenon ranging from, for example, using email instead of posted mail, utilizing videoconferences to enable remote face-to-face meetings, tapping into web platforms to sell products and services online, or outsourcing and automating routine tasks dealing with large data masses to software robots operating with artificial intelligence. Different organizations adopt digital ways of working, products, services and processes in different manner and pace. Issues with adopting digital ways of working may include change resistance among the employees, customers' and partners', general attitude towards digitalization, and the gap between current use of digital tools and the target level. Digitalization will surely change work in almost every organization at some point of time, but the extent and pace of capitalizing its potential has much to do with human attitude, ability to learn and the possibilities provided to use it in work context.

This paper discusses the expectations and fears that employees working in Finnish organizations have towards digitalization changing their work. The issue is approached by first conducting a literature review on the benefits and hindrances that digitalization may bring to work. Then, using an empirical case study, employees' attitudes towards these issues are clarified. The aim is to find out if they see the effects digitalization has on their work as positive, negative, or something else, and which areas are possibly highlighted.

This study aims to answer the following research questions:

1) What are the expected benefits and feared hindrances regarding work performance caused by digitalization of work?

2) How do the employees experience these benefits and hindrances in their everyday work?

The paper is constructed as follows: First, a brief theoretical discussion on the expected benefits and potential harmful effects of digitalization of work are presented. After that, the methodology and data gathering choices regarding the case study are described, followed by a presentation of the results of the empirical study. Finally, the conclusions and implications of the paper are provided along with suggestions for further research. 


\section{Two-fold Effects of Digitalisation of Work}

Digitalization is expected to enhance work performance by promoting productivity and efficiency as well as enabling better use of knowledge. Information and knowledge are the focal resources of contemporary organizations, and therefore, their effective flow is crucial for their performance: Effective knowledge flows may promote job satisfaction [20,21], which, again, is linked to productivity [22,23]. The expectation is that digitalization enhances knowledge flows by providing effective tools to act as mediums and enablers of work. Productivity advances hand in hand with the speed by which information flows through the process [24]. The better and more effective the knowledge flows within an organization are, the quicker employees are able to plan and perform their tasks [25]. However, even if effectively managed knowledge flow improves productivity [26,27], poorly managed knowledge flow may cause information overload leading to reduction in productivity on both the individual and organizational levels [28].

Organizations often seek to supplement their resources and knowledge base by networking. Mobility and asynchrony, i.e. independence of time and place, are prerequisites for a modern networked organization, which again call for efficient digital tools. These tools enable and enhance co-creation, as they provide the means to, for example, simultaneously create and edit documents or arranging teleconferences, enabling asynchronous and multi-spatial work and making it more efficient. Efficiency is the optimal allocation of resources, i.e., any resource is available, but used only if needed [29]. However, even if a tool is understood to enhance efficiency, people tend to hold on to their old work conditions and habits because they often experience the demand for the constant integration of new technology as stressful [30]. In addition, personal preferences, organizational conventions, and the socio-technological environment might steer one toward using a certain tool.

In general, digital tools are designed to enable work, yet technology can also pose barriers that hinder the flow of knowledge from source to recipient (e.g. [31]) According to Riege [32], technology-related knowledge barriers include, among others, unrealistic expectations for information systems' performance and insufficient training and support regarding information systems. Technological shortcomings, such as poor usability or malfunctions, of a tool also negatively affect its expected support of work and, in fact, induce strain $[33,17]$.

Regardless of all the benefits and support these tools are designed to bring to work, they also seem to cause negative symptoms and disturbances of well-being (e.g. $[34,35]$ ), which are often referred to as technostress [36,37]. Digital tools provide better resources by making more information and knowledge available more easily. However, this may simultaneously cause information overload, as the human ability to process information has not increased [38] 
The sense of losing control due to the abundant amount of information brings on inefficiency, procrastination and stress [39]. To benefit from digitalization, it is essential to identify and manage the information load in knowledge-related work. For individuals to better cope with the demands of work, there is a need to develop methods suited for different processes and conventions. Although digitalization may provide more freedom, independence and autonomy to work by enabling flexibility, mobility and asynchrony, it consequently creates an "always on" -mode in which work penetrates leisure time. The expectation of availability and the implicit pressure to reply immediately leads to time-management challenges and affects workers' well-being if they feel they do not have enough time to recharge between working hours $[40,42,42,43]$. The relation between the characteristics of ubiquitous, immersive, digital work environments and performance is a relevant theme for research to understand and, consequently, provide the means to diminish its supposed harmful effects.

As discussed on previous research on the phenomena we summarize that the factors in digitalized work environment enabling performance are Autonomy, Asychrony, Co-creation, Efficient and fast knowledge flow, Independency, and Mobility. Correspondingly, the factors constraining performance are identified as "Always on" -mode, Information overload, Procrastination, Stress and well-being, Technological shortcomings, and Time management challenges [44]. Next, using empirical data, we aim to explore the presence of these enabling and constraining factors in the daily work of employees.

\section{Research Methodology}

\subsection{Data}

Research was carried out in Finland between 2015-2018 and the data was collected using online survey. The topic was how working environment affects work and work performance. The survey included 49 Likert scale variables and four open-ended questions. In this, paper the focus is on those open-ended questions. Answering all the questions, including the open-ended, was optional. A questionnaire was sent to the participants by email, and they typically had about two weeks' time to respond. The response rates varied from $33 \%$ to $89 \%$. The respondents were mainly from public organizations and some were from public corporations (which were previously public organizations). All the organizations were planning or went through large changes in their workplace, so they needed overviews on how their employees were experiencing their work environments, individual work practices, well-being and productivity. The organizations also planned to use or had used their own results to measure the impacts of the changes. The research data was collected for the organizations' own purposes to assist the change and the participants were informed that the data would be used for scientific purposes as well. The data includes responses before the change from 28 organizations and from 8 organizations also after the change. The total amount of respondents was 8568 , and 5332 of them had responded to at least one of the four openended questions. All the respondents were considered as knowledge workers on different levels from assistants and junior level experts to project managers and to top management. All the respondents were Finnish-speaking. 


\subsection{Data analysis}

The quantitative analysis of the data was based on simple heuristic analysis by categorizing different factors brought about to categories of performance enablers or performance constraints. The factors presented as conclusion in section 2 were used as sub-categories. Each entry was read through and categorized. Based on researcher judgement each entry was also assessed according to criticality or weight as minor, moderate or critical. In analysis, minor enabler is something that is "nice to have". Moderate enabler is something that "should be". And critical enabler is something "must have". The constraints were treated accordingly their effect, i.e. minor, moderate or critical

After classification of entries simple frequencies of enablers and restraints and distributions to minor, moderate and critical was calculated. Further analysis is based on these two items, i.e. how often it is mentioned and setting weight on how critical the factor is. Analysis is based on qualitative analysis, since classification is based on single researcher work. To some extent, it would be possible to apply quantitative analysis too, yet it would require classification at least by one other researcher, preferably several. Then it would be possible to use for example chi square test to test the significance of differences between the categories. More thorough assessment would also require additional testing for reliability of the classification by Kripperdorf's alpha. In this paper, qualitative analysis is the main method. The following section presents result, visualization of the distributions and analysis.

\section{Results}

Overall, 9843 entries of 10684 open-ended entries were related to factors that enable or restrain knowledge work in digital work environment. The other entries were more related to miscellaneous productivity issues, yet those had no relation to sociotechnical work environments. Most entries were about general managerial issue and the organizatizing of work in general. The entries contained relatively rich information on work environment and a total of 11834 entries on factors relating sociotechnical work setting were found.

Respondents entered 5235 factors that enable their work. Factors related to mobility had 289 entries, factor related to asynchrony had 1380 entries, factor related to co-creation had 122 entries, factors related to efficient and fast knowledge flow had 895 entries, factors related to independency had 1005 entries, and factors related to mobility had 1544 entries. Overall the emphasis was on enablers that supported spatial dispersion and asynchronic work on people's own working pace. Figure 1 summarizes enabling factors and the distributions to different importance categories. 


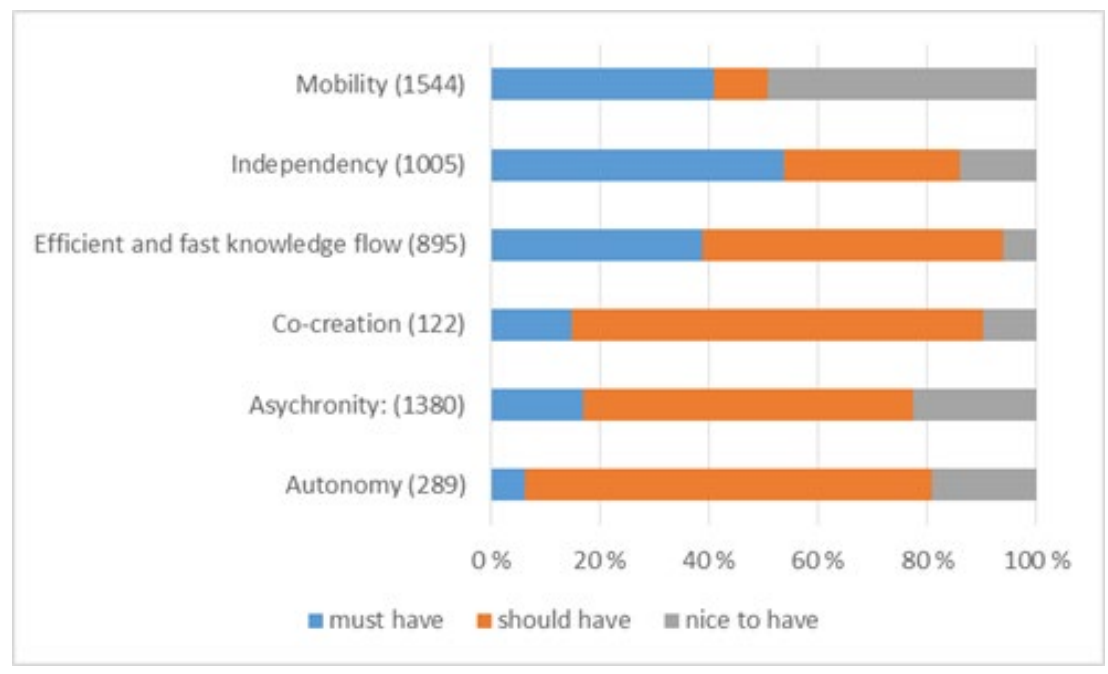

Fig. 1. Summary of number of entries per enabling factor and distribution of importance by enabling factors

Autonomy was considered mostly to have moderate effect on work and overall it was not major issue per se as it was mentioned 289 times. Respondents acknowledged their dependency on coworkers and customers. Only seldom they had full autonomy in their work. Asychronity had 1380 entries and it was seen as the second key enabler. In this dataset asynchrony had effect on work performance, since people could work by different digital platforms with their peers. Digitalization boosted asynchronic working and in general it was seen beneficial. Asynchorny has moderate effect as performance enabler as most of entries set on should have category. Co-creation had least effect as work performance enabler as there was only 122 entries. There might be several explanations, yet most evident is that even working in teams people considered themselves to work alone. However, in many responses people appreciated "relay" working, i.e. working with peers during iteration. On the other hand many people described themselves as single expert on their filed and thus there is no need to constantly work in groups.

Efficient and fast knowledge flow was mentioned 895 times, yet many saw it as a critical enabler. This is due to nature of the work respondents were doing. Making decisions or planning is highly dependent on the available information from different sources. Moreover, as people were spatially dispersed in their organizations the importance of correct and on-time information has a great effect as an enabler. Independency as an enabler had 1005 entries and it was seen important since most of the entries were in the "must have" category. This is mostly due to nature of the knowledge work in general, but mostly due to nature of knowledge work in these organizations. People work on their own core tasks and independency provided by digitalization gives them control on their work flow. As the work is not dictated by a certain process, but it is more organized the people executing it the effect on work performance is remarkable. Moreover, independency is also issue of better work-leisure fit, since people have more options on arranging their work. 
Mobility had most entries as it was mentioned 1544 times. The different aspects of mobility in work enable performance since people have freedom of choice to conduct their task in different places, e.g. working distant, working in transportation, working at customer site, fieldwork, etc. This sets people free of spatial restrictions and most of the mobility is supported by digitalization as people have distant access to information, they have sufficient tools, infrastructure is accessible and not bound to certain location. Moreover, the performance effect is also due better utilization of time as people can use excess time or take action immediately.

Factors considered as restraints gained roughly $25 \%$ more entries totaling 6599 of them. "Always on" work communication mode or constant connectivity was mentioned 611times. Most critical and most mentioned performance restraint was information overload as it gained 1994 entries. Procrastination was considered a minor restraint since it was mentioned in 421 entries. Stress and well-being was mentioned 1478 times. The third most important restraint category was technological shortcomings with 1389 entries. Time management challenges was mentioned 677 times. Figure 2 summarizes the restraining factors and distribution according to criticality.

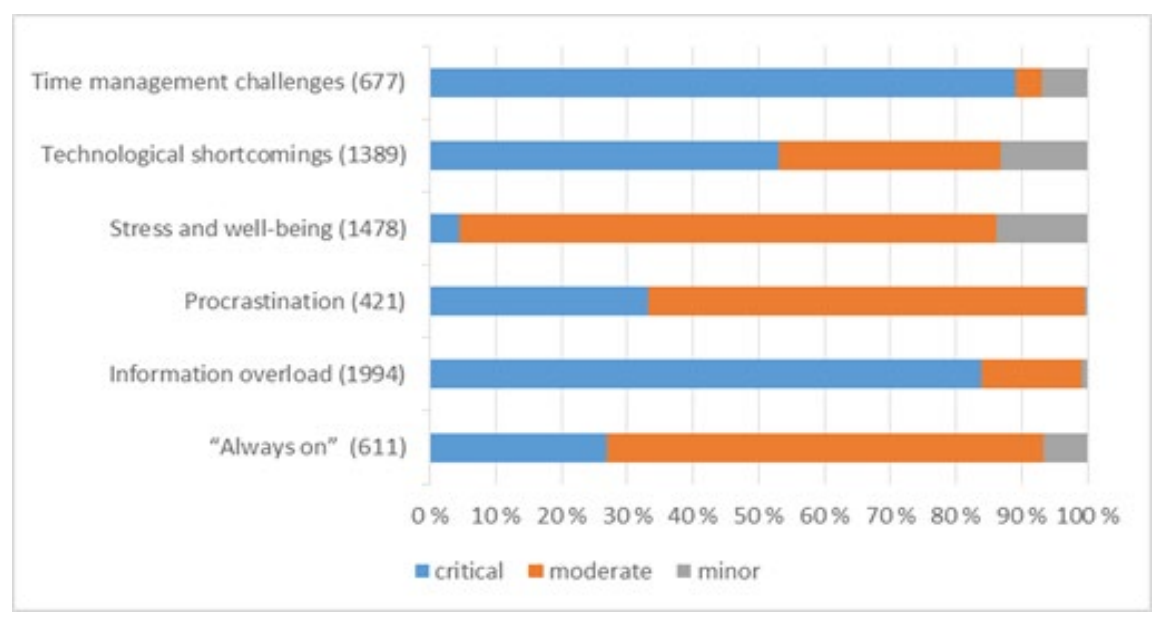

Fig 2. Summary of number of entries per restraining factor and distribution of importance by enabling factors

"Always on" -mode is not critical to work performance, yet many respondents recognized it as a restraint. In many cases people felt that they were obliged to be available even if they wanted to work on an individual project, be on break, or even during their time off the work. In several entries constant connectivity was related to the urge to be quick and productive.

Information overload was seen as the most critical issue restraining work performance. It has several direct effects as well as indirect ones. Respondents brought about in their entries that overload is due to poor digital skills, insufficient IT infrastructure, poor applications and services, poor explicit rules of information 
conventions, and poor habits. Information overload can be therefore seen as a cause, a symptom, and an effect of poor information ergonomics.

Procrastination by respondent or by the others seems to be critical and has an effect on performance. In digital environment procrastination is of conducted via email by sending insufficient or incomplete information. On the other hand, people described it also to be a working strategy, yet a harmful to performance though. However, procrastination did not gain so many entries. Stress and well-being was considered the second most critical restraint. In the entries the well-being at work was related to control of own work, getting things done, or general working conditions. In the entries wellbeing was something that could be perceived and also talked out. On the other hand, stress and well-being are more likely to be mere symptoms while the root cause is something else. However, very many people claimed that stress is causing poor performance.

Technological shortcomings have a direct effect on work as working infrastructure is a prerequisite for productivity. There were entries on how old, outdated, or impractical technology slows working or even totally restraints it. However, the number of entries was relatively low as digitally set work environment is very vulnerable in sense of technology. This somehow reflects technological fatalism, i.e. people can live with shortcomings in digital work environment if it is not totally out of order. Time management was seen as a critical issue in digital knowledge work. Respondents emphasized several issues about how digital environment, especially email, digital working platforms, customer information systems, and digital communication in general affect the work flow and cause distractions. The prioritization of work is done by digital environment, not the people executing the tasks. As presented above digitalization has an outstanding effect on knowledge work. It supports and leverages it by giving individuals freedom and access. On the other hand, digital work environments have enabled working without spatial restraints. As described above the technological advances have their flip side too, yet it is mostly an issue of how to adapt work environment, conventions and habits to better meet expectations and requirements.

\section{Discussions and Conclusions}

The purpose of this paper was to analyze and compare different factors that either enable or restrain knowledge work in different work settings, and further, to discuss the effect of these identified factors on work performance in knowledge work. In the theoretical part of the study enabling factors i.e. autonomy, asychrony, co-creation, efficient and fast knowledge flow, independency, and mobility were set for key factors. Correspondingly, the factors constraining performance were as "always on" -mode, information overload, procrastination, stress and well-being, technological shortcomings, and time management challenges were discussed as restraints of knowledge work. They have either a positive or a negative effect on the performance of knowledge work actions.

It was seen that there are many similar elements that support or hinder the knowledge work in different organizations, moreover many items entered have a flip 
side as well. A factor that someones considers to be an enabler may be a restraint for someone else. The enablers were typically the factors that facilitate the professionals' core work, such as information acquisition, refining and dissemination. Communication was considered important, especially asynchronic communication with peers and clientele. In addition, the enablers that were mentioned by the informants helped the knowledge workers to cope with their work pressure, handle the stress and regulate the work flow. Indeed, the enablers were strongly related to the wellbeing at work as well as sense of control and productivity. The core tasks of the knowledge workers consisted of knowledge work actions, such as information acquisition, combining, creation, dissemination, and communication. The wellbeing at the work and coping with the heavy workload have an indirect effect on the knowledge work actions and further, in work performance. The hindrances were related with the professionals' core tasks as well as wellbeing through the work and balancing work and leisure.

It seems that the knowledge work enablers aid more the core tasks of the people while the restraints are more commonly related to the wellbeing, stress and pressure at work. Factors affecting the core work and wellbeing at work were linked with one another to some extent. For many respondents, the factors causing stress and pressure had an indirect impact on their core work. If the core tasks are made difficult or disturbed, it can increase the pressure at work. On the other hand, having suitable sociotechnical work environment in terms of infrastructure, well-functioning work conventions, self-regulated working habits and sufficient skills supports productive working.

The study raised a lot of factors that can act as enablers or restraints of knowledge work. These elements similarly affect productivity as well as the well-being at work either positively or negatively. Key implications regarding knowledge work are about performance. There seems to be three main categories of performance. The first category is individual performance supported by individual knowledge, skills, and working habits. The second performance category is about organization supported by explicit operation procedures and socially constructed conventions. The third performance category is about social capital in sense of recognition of peers and key stakeholders in working domain and working with them. There categories are not exhaustive, yet as conclusion of enablers and restraints they bring about the key issues related to knowledge work in general. These implications have limited direct transferability to knowledge work.

The results implicate that more attention should be paid on managerial practices in organizing knowledge work. Planning sociotechnical work environment is the key, since asynchrony and spatial dispersion of work require more working via digital platforms or using communication tools. This is in close relation to ergonomics of knowledge work, i.e. how infrastructure is set, how working is explicitly instructed, and how working conventions dictate workflow and conducting the tasks. As brought about only part of issues could be planned, since conventions are dependent on the whole realm of work as well as habits are result of individual development.

The results presented in this paper are based on single researcher qualitative analysis. The validity of the factors is validated in previous research. The classification of the entries is valid as it is based on single researcher interpretation. Researcher triangulation and testing the uniformity by Krippendorfs alpha could increase the 
reliability of classification. As the data is now presented can be considered somewhat reliable and therefore the results are valid with certain restrictions. Restrictions come merely from the domain, since the data is not representative in general but exhaustive on public sector and publicly owned companies.

With these findings, this paper contributes primarily to the research on sociotechnical work environments. First, it is about setting knowledge work digital environment and how to prioritize different performance factors or assess the importance of those. Second, it contributes to research on information ergonomics as it elaborates how technology, people, and individual are actually forming complex activity system based on tacit, implicit and explicit rules, norms, conventions, and habits that shape activity called work. Moreover, as results underline information overload as a major issue in knowledge work organization also managerial implications can be drawn from it.

Further research on the domain should concentrate on making the classification finer in order it to better explain different interconnections between enabling and restraining factors. Moreover, the data could be better utilized through revision on interpretation by several researcher. By doing so actually more sophisticated analysis could be applied on data and go beyond simple heuristicsms!

\section{References}

1. Sassen, S. (1998) Globalization and its discontents: Essays on the new mobility of people and money. New York, NY: New Press.

2. Neumeier, A. Wolf, T., Oesterle, S. (2017) The Manifold Fruits of Digitalization : Determining the Literal Value Behind. 13. Internationale Tagung Wirtschaftinformatik WI

3. Porta, M., House, B., Buckley, L. and Blitz, A. (2008) "Value 2.0: Eight new rules for creating and capturing value from innovative technologies", Strategy \& Leadership, Vol 36 No 4, pp. $10-18$.

4. Parida V, Sjödin DR, Lenka S, Wincent J (2015) Developing global service innovation capabilities: How global manufacturers address the challenges of market heterogeneity. ResTechnology Management, 58(5): 35-44.

5. Grudin, J. (2006) "Enterprise knowledge management and emerging technologies", In Proceedings of the 39th annual Hawaii international conference on system sciences (pp. 57). Washington, DC: IEEE Computer Society.

6. Shujahat, M., Sousa, M. J., Hussain, S., Nawaz, F., Wang, M. and Umer, M. (2017) "Translating the impact of knowledge management processes into knowledge-based innovation: The neglected and mediating role of knowledge-worker productivity", Journal of Business Research

7. Michaelis, B., Wagner, J. D. and Schweizer, L. (2015) "Knowledge as a key in the relationship between high-performance work systems and workforce productivity", Journal of Business Research, Vol 68 No 5, pp. 1035-1044.

8. Chou, Y.-C., Chuang, H. H. C. and Shao, B. B. M. (2014) "The impacts of information technology on total factor productivity: A look at externalities and innovations", International Journal of Production Economics, Vol 158, pp. 290-299.

9. Ferreira, A. and Du Plessis, T. (2009) "Effect of online social networking on employee productivity", South African Journal of Information Management, Vol 11 No 1, pp. 1-16.

10. Tuomi, I. (2004) "Economic productivity in the knowledge society: A critical review of productivity theory and the impacts of ICT", First Monday, Vol 9 No 7 
11. Haas, M. R. and Hansen, M. T. (2007) "Different knowledge, different benefits: Toward a productivity perspective on knowledge sharing in organizations", Strategic Management Journal, Vol 28 No 11, pp. 1133-1153.

12. Porten, M. and Heppelmann, J. (2015) How Smart, Connected Products Are Transforming Companies. HBR October 2015

13. Voth, D. (2002) "Why enterprise portals are the next big thing", Learning \& Training Innovations, Vol 3 No 9, pp. 24-29.

14. Franssila, H., Okkonen, J. and Savolainen, R. (2015). "Developing measures for information ergonomics in knowledge work", Ergonomics, Vol 59 No 3, pp. 435-448.

15. Bordi L, Okkonen J, Mäkiniemi JP, Heikkilä-Tammi K (2017) Employee-developed ways to enhance information ergonomics. In Proceedings of the 21 st International Academic Mindtrek Conference pp. 90-96. ACM

16. Salanova M, Llorens S, Cifre E (2013) The dark side of technologies: Technostress among users of information and communication technologies. Int J of Psychology, 48(3): 422-436.

17. Tarafdar, Tu, Ragu-Nathan and Ragu-Nathan 2011

18. Chen, W. (2013) "Internet use, online communication, and ties in Americans' networks", Social Science Computer Review, Vol 31 No 4, pp. 404-423

19. Ragu-Nathan, T. S., Tarafdar, M., Ragu-Nathan, B. S. and Tu, Q. (2008) "The consequences of technostress for end users in organizations: Conceptual development and empirical validation", Information Systems Research, Vol 19 No 4, pp. 417-433.

20. Bontis, N., Richards, D. and Serenko, A. (2011) "Improving service delivery: Investigating the role of information sharing, job characteristics, and employee satisfaction", Learning Organization, vol 18 No 3, pp. 239-250.

21. Palvalin, M., Vuori, V. and Helander, N. (2017) "Knowledge transfer and work productivity", In J. C. Spender, G. Schiuma, and T. Gavrilova (Eds.), Proceedings of 12th international forum on knowledge asset dynamics (pp. 1120-1134). St. Petersburgh, Russia.

22. Laschinger, H. K. S., Finegan, J. and Shamian, J. (2002) "The impact of workplace empowerment, organizational trust on staff nurses' work satisfaction and organizational commitment", Advances in Health Care Management, Vol 3, pp. 59-85.

23. Miller, K. I. and Monge, P. R. (1986) "Participation, satisfaction, and productivity: A metaanalytic review", Academy of Management Journal, Vol 29 No 4, pp. 727-753.

24. Schmenner, R. W. (2004) "Service businesses and productivity", Decision Sciences, vol 35 No 3, pp. 333-347.

25. Wu, F., Huberman, B. A., Adamic, L. A. and Tyler, J. R. (2004) "Information flow in social groups", Physica A: Statistical Mechanics and its Applications, Vol 337 No 1-2, pp. 327-335

26. Dyer, J. \& Nobeoka, K (2000) "Creating and Managing a High-Performance KnowledgeSharing Network: The Toyota Case" Strategic Management Journal, Vol 21, Iss 3 (Special Issue), pp345-367

27. Titus, S. and Bröchner, J. (2005) "Managing information flow in construction supply chains", Construction Innovation, Vol 5 No 2, pp. 71-82.

28. Ben-Arieh, D. and Pollatscheck, M. A. (2002) "Analysis of information flow in hierarchical organizations", International Journal of Production Research, Vol 40 No 15, pp. 3561-3573.

29. 1) Okkonen, J. (2004) The Use of Performance Measurement in Knowledge Work Context. e-Business Research Center, Research Reports. 9. Tampere. Tampere University of Technology (TUT) and University of Tampere (UTA).

30. Tarafdar, M., Tu, Q., Ragu-Nathan, T. S. and Ragu-Nathan, B. S. (2011) "Crossing to the dark side: examining creators, outcomes, and inhibitors of technostress", Communications of the ACM, Vol 54 No 9, pp. 113-120.

31. Paulin, D. and Suneson, K. (2012) "Knowledge transfer, knowledge sharing and knowledge barriers-three blurry terms in KM", Electronic Journal of Knowledge Management, Vol 10 No 1, pp. 81-91. 
32. Riege, A. (2005) “Three-dozen knowledge-sharing barriers managers must consider”, Journal of Knowledge Management, Vol 9 No 3, pp. 18-35.

33. Day, A., Scott, N. and Kelloway, E.K. (2010) "Information and communication technology: implications for job stress and employee well-being", in P.L. Perrewé \& D.C. Ganster (Eds.) New Developments in Theoretical and Conceptual Approaches to Job Stress, pp. 317-350, Emerald Group Publishing.

34. Mark, G., Iqbal, S. T., Czerwinski, M. and Johns, P. (2014) "Bored mondays and focused afternoons: The rhythm of attention and online activity in the workplace", In Proceedings of the 32nd annual ACM conference on human factors in computing systems (pp. 3025-3034). Toronto, Canada: ACM.

35. Mark, G., Voida, S. and Cardello, A. (2012) "A pace not dictated by electrons: An empirical study of work without email", In Proceedings from SIGCHI '12: Conference on human factors in computing systems (pp. 555-564). Austin, TX: ACM.

36. Gaudioso, F., Turel, O., and Galimberti, C. (2017) Explaining Work Exhaustion From a Coping Theory Perspective: Roles of Techno-Stressors and Technology-Specific Coping Strategies. Stud Health Technol Inform. 2015;219:14-20.

37. Maier C, Laumer, S, Weinert, C, Weitzel, T (2015) The effects of technostress and switching stress on discontinued use of social networking services: A study of facebook use. Inf Systems J, 25(3): 275-308.

38 Woods DD, Patterson ES, Roth EM (2002) Can we ever escape from data overload? A cognitive systems diagnosis. Cognition, Technology \& Work, 4(1): 22-36

39. Mark, G., Iqbal, S., Czerwinski, M., Johns, P. and Sano, A. (2016) "Email duration, batching and self-interruption: Patterns of email use on productivity and stress", In Proceedings of the 2016 CHI conference on human factors in computing systems (pp. 1717-1728). San Jose, CA: ACM.

40. Barber LK, Santuzzi AM (2015) Please respond ASAP: Workplace telepressure and employee recovery. J of Occupational Health Psychology, 20(2):172

41 Barley, S.R., Meyerson, D.E. and Grodal, S. (2011) "Email as a source and symbol of stress", Organization Science, Vol 22 No 4, pp. 887-906.

42. Brown R, Duck J, Jimmieson N (2014) E-mail in the workplace: the role of stress appraisals and normative response pressure in the relationship between e-mail stressors and employee strain, Int J of Stress Management 21(4): 325-347.

43. Wajcman, J. and Rose, E. (2011) "Constant connectivity: Rethinking interruptions at work", Organization Studies, Vol 32 No 7, pp. 941-961.

44. Vuori, V., Helander, N., Okkonen, J. (2018) Digitalization in Knowledge Work: The Dream of Enhanced Performance. Cognition Technology \& Work DOI 10.1007/s10111-018-0501-3. 